\title{
Study on Present Situations and Problems of Beijing-Tianjin-Hebei Logistics Enterprises Information Construction
}

\author{
Hongjian Liu, Xiaoqing Zhao, Lingyao Zhu, Xiaofan Wang
}

School of Information, Beijing Wuzi University, Beijing, China

Email address:

522927485@qq.com (Hongjian Liu),2444581373@qq.com (Xiaoqing Zhao),1052992312@qq.com (Lingyao Zhu)

\section{To cite this article:}

Hongjian Liu, Xiaoqing Zhao, Lingyao Zhu, Xiaofan Wang. Study on Present Situations and Problems of Beijing-Tianjin-Hebei Logistics Enterprises Information Construction. International Journal of Economics, Finance and Management Sciences.

Vol. 4, No. 4, 2016, pp. 170-176. doi: 10.11648/j.ijefm.20160404.11

Received: May 9, 2016; Accepted: June 6, 2016; Published: June 21, 2016

\begin{abstract}
Beijing-Tianjin-Hebei Area becomes one of the largest city accumulation areas of China and economic region owns a good informationalized level, high trade demand and strong technical forces. At present, it is not only the need of the development of modern logistics industry, but the common aspirations of logistics enterprises in Beijing-Tianjin-Hebei Region to break administrative division boundaries to guide the cross-regional integration, optimize configuration of logistics resources and realize the coordinated development of Beijing-Tianjin-Hebei logistics industry. In recent years, the regional cooperation is being strengthened constantly and the development step of the Beijing-Tianjin-Hebei logistics industry has quickened continuously, hence area logistics integration development is becoming reality. As the foundation of modern logistics operation and rapid development, logistics informatization is considered to be precondition and crucial tache to enable greater efficiency and lower cost in logistics system. This paper will focus on the overview of the informatization construction of Beijing-Tianjin-Hebei logistics enterprises by the method of case study, and conduct a study of the general problems existing in the integration of the Beijing-Tianjin-Hebei region after the data analysis, which could make an important significance on the development of Beijing-Tianjin-Hebei logistics informatization. Finally the article gives the advices for improvement.
\end{abstract}

Keywords: Beijing-Tianjin-Hebei, Logistics Informatization, Logistics Enterprise

\section{Introduction}

With the vigorous development of logistics enterprises in Beijing-Tianjin-Hebei region, the logistics enterprise scale is growing fast. Compared with 2012, the number of corporate units in the transportation, warehousing and postal industries has risen rapidly in 2013, led by Beijing which reported a 74.73 percent increase to add 6052 corporate units, and followed by Hebei that added 1828 corporate units, an increase of $25.57 \%$, while Tianjin only holds an increase of $9.3 \%$, about 714 corporate units, which lies last in the percentage. At the same time, the improvement and upgrade of industrial structure is driving force for steady and fairly rapid growth of the volume of business in Beijing-Tianjin-Hebei logistics enterprises. Logistics information platform has become the new emphasis and new revenue growth point, which can show up in revenue growth rate of 2014, that is, logistics enterprises' information and related services revenues and integrated logistics business revenue increased by an annualized $94.0 \%$ and $31.0 \%$ respectively [1]. Construction of logistics information platform is considered to be crucial for the industry to ease the gradually increasing cost pressures of logistics enterprises, reduce its high labor costs proportion and improve business efficiency of logistics. This indicates that integrated logistics and information services are becoming the logistics business new revenue growth highlights in support of the synergic development strategy of Beijing-Tianjin-Hebei integration.

In the present time, our enterprise logistics informatization is developing quickly, and some achievement has been made. An investigation of the information-based construction of the logistics enterprise, conducted by China Federation of Logistics and Purchasing shows that great progress have been made in building the foundation of company business 
informatization. Approximately $70.5 \%$ of the enterprises have established the management information system, and the self-developed and purchase of software products business software enterprises accounted for $40.2 \%$ and $37.6 \%$ respectively, which followed by the joint development and the purchase of services, while the long-term outsourcing occupied lowest proportion. In addition, enterprises with no integration system made up about $15.6 \%$, compared with enterprises with a certain amount of integration system constituted $62.5 \%$ and enterprises with perfect integrated systems accounted for $21.9 \%$ (shown as Figure 1). At present, most logistics companies attach great importance to the application of new technology, for example, the percentage of bar codes is slightly less than a half, which is about $40.3 \%$, next comes GPS + GIS, whose percentage is about $31.8 \%$. RFID or RF accounts for $18.6 \%$, while mobile phone positioning only holds $9.3 \%$, which lies last in the percentage. From this, it can be seen that logistics information technology not yet ubiquitous among logistics enterprise. (See Figure 2)

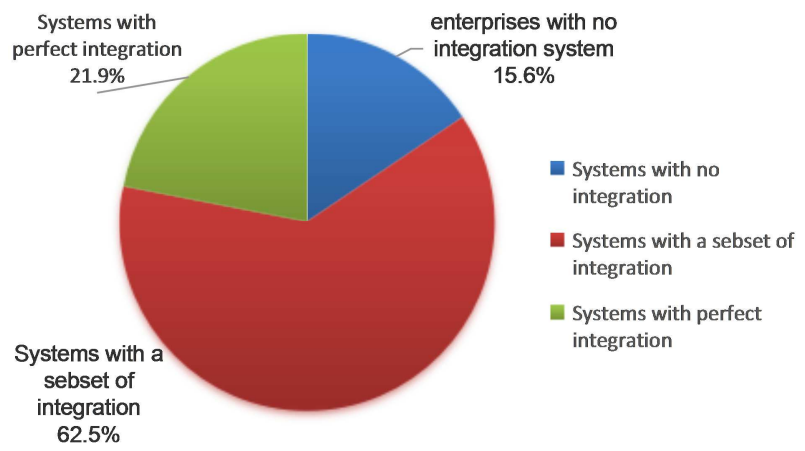

Fig. 1. Integration scenarios between Enterprise Information Systems.

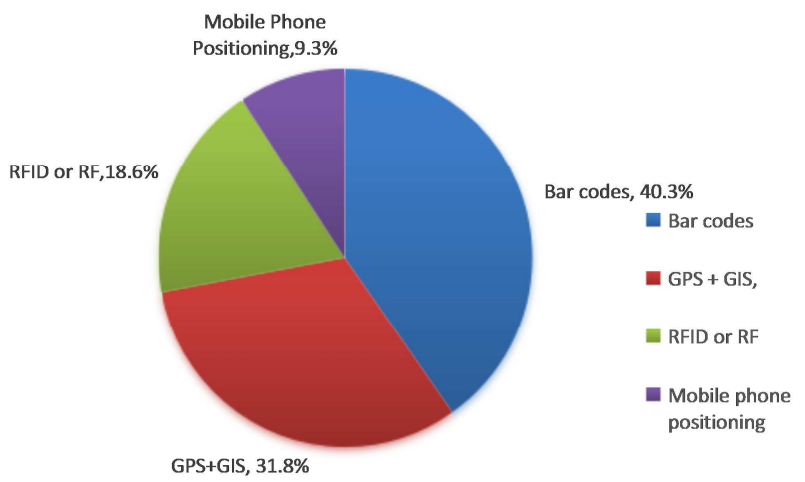

Fig. 2. The application of new information technology of logistics enterprises.

The Beijing-Tianjin-Hebei regional informationization average level of logistics enterprises is not high and gap is still wide when compared with the international advanced level in the similar economic regions, which is manifested in its poor infrastructure, inferior specialization, staggered system of management system, lack of unified planning and logistics standards, the "big logistics "system has not been formed and the logistics enterprise information needs to be improved [2]. Therefore, it is imminent for the logistics industry to realize informatization and to speed up the pace of logistics information construction, which is not only the base of institutional innovation, technological innovation and management innovation, but also the only option to enhance core competitiveness of enterprises logistics.

Modern logistics put forward high requirements of informatization, and it not only requires intelligence of all aspects of logistics management, but also requires business information of logistics operations, including the realization of high efficiency and professionalization in logistic purchasing, logistics production, logistics sales and logistics recycling. Due to limitations of existing operation system, most of the Beijing-Tianjin-Hebei regional logistics enterprises' information systems and technologies are primarily completed in the internal organization, which means that the logistics information is not specialized and scale-developed. There are some studies point out that the Beijing-Tianjin-Hebei regional logistics informatizaion would be required to take the road of development with information resources sharing and information network integration. This paper would provide an overview of the informatization construction of Beijing-Tianjin-Hebei logistics enterprises and problems existing in the integration of the Beijing-Tianjin-Hebei region, which would provide a certain degree of significance for future study.

\section{Information Construction Status of Large-Scale Logistics Enterprise in Beijing-Tianjin-Hebei Region}

Informatization is an essential feature of modern logistics as well as an important trend of modern logistics development. Most of the logistics enterprises in the areas of Beijing-Tianjin-Hebei have started in the informatization construction, but the average level is still low and polarized. Findings revealed that as the core of the process of logistics informatization, logistics information systems are increasingly becoming bottlenecks in the development of logistics enterprises [3]. There are only a few companies have logistics information systems in Beijing-Tianjin-Hebei area, compared with the vast majority of logistics enterprises do not yet have the ability to use modern information technology. In the logistics enterprise with information system, there are less about customer relationship management and nearly half of the companies do not have their own independent websites; most of the information systems are isolated and static with low level of information sharing and low integration capability of logistics information resources, hence the overall planning capacity need to be improved.

\subsection{Application Status of Information System}

The website of the large and medium-sized logistics enterprises whose informatization level is higher in Beijing-Tianjin-Hebei is still used for propagandizing corporate image and other basic functionality, nevertheless, the proportion of website as e-commerce platform is relatively small, which accounts for $16.67 \%$. At the same time, the applications of completed information systems 
focused on warehouse management, financial management, transportation management and order management, etc., while the proportion of applications related to customer relationship management which concerns enterprises existence and development is very small, about $23.33 \%$ [4].

Currently, logistics information system applied by large and medium-sized logistics enterprises in Beijing-Tianjin-Hebei Region includes Inventory ERP system (MaxTM), Warehouse Management System (WMS), Transportation Management System (TMS), Location Based
Services (LBS), Storage Resource Management System (SRM), Demand Chain Management System (DCM), etc. The table below shows the application status of logistic information system of several large-scale logistics enterprises in Beijing-Tianjin-Hebei region, includes Beijing Futian Logistics Co., Ltd., Beijing Stone Logistics Ltd., Beijing Changjiu Logistics Co., Ltd., Beijing Jingliang Logistics Co., Ltd. Hebei logistics industry Group Co., Ltd., Tianjin DTW logistics group co., LTD. These companies are selected from the China Top 100 Logistics Enterprises. (See Table 1)

Table 1. List of information system implicated in Beijing-Tianjin-Hebei large-scale logistics enterprises.

\begin{tabular}{|c|c|c|c|c|c|c|c|}
\hline Region & Company & MaxTM & WMS & TMS & LBS & SRM & DCM \\
\hline Beijing & $\begin{array}{l}\text { Beijing futian wisdom logistics co., LTD. } \\
\text { Beijing Stone logistics co., LTD. } \\
\text { Beijing Changjiu logistics co., LTD } \\
\text { Beijing Jingliang logistics co., LTD }\end{array}$ & & $\begin{array}{l}\sqrt{ } \\
\sqrt{ } \\
\sqrt{ }\end{array}$ & $\begin{array}{l}\sqrt{ } \\
\sqrt{ } \\
\sqrt{ }\end{array}$ & $\sqrt{ }$ & $\sqrt{ }$ & $\sqrt{ }$ \\
\hline $\begin{array}{l}\text { Hebei } \\
\text { Tianjin }\end{array}$ & $\begin{array}{l}\text { Hebei Logistics Industry Group Co., LTD } \\
\text { Tianjin DTW logistics group co., LTD }\end{array}$ & $\sqrt{ }$ & $\sqrt{ }$ & & & & \\
\hline
\end{tabular}

As can be seen from this table, the information systems application of logistics companies in Beijing is better compared with Tianjin and Hebei. Large logistics companies in Beijing are more successful in information systems application with larger number of information systems. WMS or TMS system is used more often among the successful implicated information systems on account for WMS system is sufficient to meet the whole process of warehouse management to achieve a seamless interface with the client, while TMS system provides asset management services assurance for customers in situations where the application of the relevant customer relationship management information systems is rare.

\subsection{Availability of Information Sharing}

Most of the information systems owned by Beijing-Tianjin-Hebei logistic enterprises are isolated and static, as well as low levels of information sharing. Information cannot be shared and coordinated operation cannot be realized among members of the logistics service chain [5]. It would result in a waste of network and logistics information resources because of the independent of manufacturing companies, logistics companies, freight forwarders, cargo service companies, Customs, commercial and taxation department, inspection and quarantine department, government, port authorities and terminal client systems, which would also affect the efficiency and effectiveness of transportation, resulting in lower operating efficiency of the entire logistics service chain.

To improve the degree of information sharing, large logistics companies have to break the self-isolation of the management system for the sake of building the repositories of information to realize the better information sharing and heterogeneous data sharing.

For example, Tianjin CRE (China Railway Express Co., Ltd., Tianjin), which is located in Hedong District, providing goods and services of air cargo agents, has built a national logistics network across the country including road, rail, aviation and other transport capacity. The company has established business cooperation with many famous international logistics enterprises; the network of international business covers more than 200 countries and regions of the world.

Although Tianjin CRE has established its own website, the site provides extremely small amount of information (see Figure 3), and basic information such as the company's business and enterprise products are not shown on the website, in addition, the degree of information sharing is low.
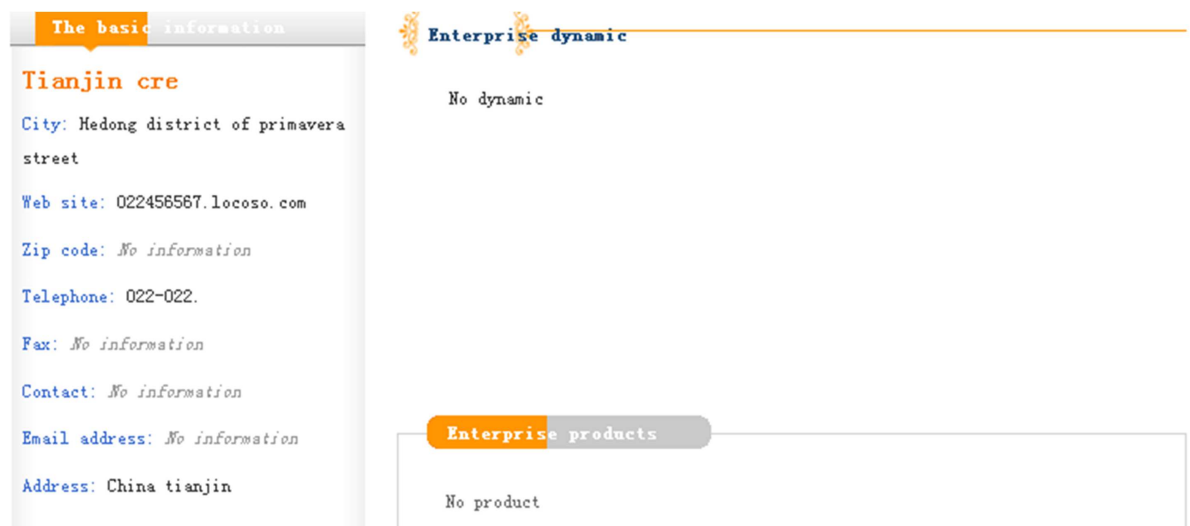

Fig. 3. Official website of Tianjin cre. 


\subsection{The Level of Overall Planning Needs to Be Improved}

Large and medium-sized logistics enterprises in Beijing-Tianjin-Hebei region have established their own logistics information system basically, but the lack of comprehensive integrated information system covered the entire enterprise makes it fail to achieve the integrated usage of enterprise storage, transportation and other logistics information systems. The overall planning ability of informatization is low and the understanding of informatization is just remains on the surface. Business is short of planning the future development of company's informatization and lack of fully integrated enterprise-wide information systems. Few engage in integrated planning of informatization.

There are some problems in connection between Logistics Information System and other information systems with different functions, most of the logistics business logistics information system are used independently, that causes certain problems in connecting with other systems, so that relevant information cannot be derived between information systems efficiently and effectively, which affects the level of corporate information processing.

Beijing Foton Wisdom Logistics Co., Ltd. (Hereinafter referred to as Foton Logistics) is a limited liability company established in May 2002 with a registered capital of 80 million yuan and annual turnover of nearly 20 billion yuan. Its operation network is spread all over China. The company passed the ISO90001 international quality management system certification, and has been awarded as "Top Ten Influential Brands of China automotive logistics industry" and also the "National Advanced Logistics Enterprises", "Chinese top 100 logistics enterprises." for 6 consecutive years. In 2014, the company had gotten tenure of "National 5A Comprehensive Service Logistics Company". (See Figure 4)

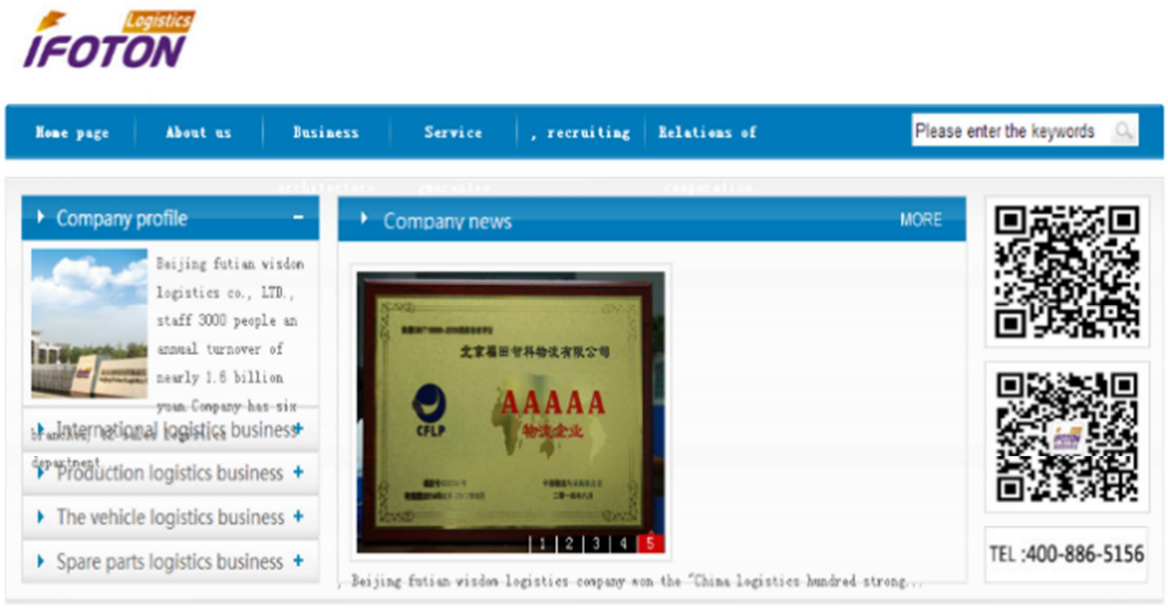

Fig. 4. Official website of Beijing Foton Logistics.

Owing to CMMP, WMS, SRM and other information systems, Foton Logistics has achieved the information acquisition precision of production order information, supplier delivery information and the production and distribution information, this effectively ensures the cost and efficiency of logistics operations. Besides, under the rapid development of the company information system, Foton Logistics main focus on business process and make full use of modern logistics technology and information technology to build the business operating system, transportation management system (TMS), Global Positioning System (GPS), warehouse management system (WMS), General Cargo Service operation management system (SOMS), call centers; systems including assist management systems, financial management systems, human resources management system, office automation system (OA), provide a strong management support and decision guarantee for the operation and control of the business.

The company came to reorganization its own that the lack of information systems integrated office systems and business systems cause the company failed to achieve the perfect coordination of information flow, material flow and capital flow. The company decided that the next step is to focus on the integration of various information methods and resources. With the help of network technology, the office systems and business systems and other management systems are integrated together to achieve perfect coordination of information flow, material flow, and capital flow.

\section{Status of SMEs' Information Construction in Beijing-Tianjin-Hebei Region}

Small and medium-size enterprise (SMEs) of logistics in Beijing-Tianjin-Hebei region accounted for more than $90 \%$ [6], most of the mcame from the traditional transport, warehousing and trading enterprises. As a consequence, majority of the SMEs have low level of information technology, poor construction of the information platform, which does not have a certain scale. Firstly, logistics informatization construction should use the most advanced information technology to ensure the collection and exchange of data and informationin order to achieve low-cost, highly 
efficient and standard internal business processes; Secondly, information-rich platform is used to guarantee the connection of customer information system and formed informationalized supply chain with high level of convenience and efficiency; Finally, a completed logistics information system is used to realize the process of decision making, optimizing and integrating of resources. Small and medium sized logistics enterprises' development in informatization is still in the initial stage, and its information system is mainly used in financial management, as well as warehousing, transportation and order management, however, it lacks of independent logistics information platform and development strategy of its logistics informatization, in addition, the information platform about basic information and public service develops slowly and the informatization degree is far lower than other developed countries' logistics enterprises [7]. The shortcomings of logistics information construction of SMEs in Beijing-Tianjin-Hebei are mainly embodied in the following three aspects.

\subsection{Lack of Advanced Information Technology}

At present, advanced information technologies includes bar-code technology, RFID, GPS / GIS technology and EDI have been widely used in the foreign logistics companies, but the most of small and medium sized logistic enterprises in Beijing-Tianjin-Hebei region are still accustomed to using manual operations rather than advanced information technology in logistics business operations management [8]. Manual operation mode not only reduces the efficiency and accuracy and increase the management difficulty, but also adds labor costs of logistics enterprises, which would increase cost pressure of logistics enterprises. In the context of the current integration of Beijing-Tianjin-Hebei region, the lag development of informatization becomes a constraint to business development for small and medium sized logistics enterprises in Beijing-Tianjin-Heibei region.

\subsection{Monotonous Construction of Information Platform}

Some SMEs produced a corporate Web site in order to meet the informatization needs and satisfy customer's demand, but most of the website businesses have a simple form and monotonous content, and the main function of the logistics company's website is to promote its corporate image advertising, followed by information services and internal communications, which gives rise to slow or even noup dating of the website and unable to meet customer demand for it involves less in the enterprise business system applications and e-commerce functionality.

\subsection{Information System Function Is not Complete}

By using the technology of computer, communications and network, logistics information system is built to effectively improve the transmission speed of data information and resolve the error rate problems that cannot be avoided in manual operation, and to reduce logistics-costs and improve logistics efficiency of business operations, as well as make use of the tracing information effectively [9]. As a consequence, logistics information platform becomes more important and urgent for small and medium sized logistics enterprises. Information systems are few implicated in Beijing-Tianjin-Hebei small and medium logistics enterprise logistics, the enterprise logistics information system, including third-party logistics information system, recycling logistics management systems, production logistics management systems, inventory logistics management systems, logistics, warehousing information systems, logistics and distribution information systems, are seldom used or even do not applied in Beijing-Tianjin-Hebei small and medium logistics enterprises. Some of the enterprises' internal information platforms are used limited to financial management and less involved in logistics operations.

Take Beijing Jingyuanda Logistics. co., Ltd (hereinafter, Beijing Jingyuanda Logistics) as an example, it is approved to franchise highway logistics line by the Beijing Municipal Transportation Authority. Since its inception, the company always adhere to standardized management and humanized service tenet, and the good faith, pragmatic, prudent management style, and the mission to fulfill their commitments, laid a solid foundation to expand the scale of the development of enterprises. Through continuous efforts it has established a complete management mechanism and service system, and be widely recognized by community for its "high-quality, safe and efficient" service for a short time, Now, Beijing Jingyuanda Logisics has developed into a modern logistics enterprises with a number of vehicles including large trucks and the city's small lift trucks of $10 \mathrm{~T}$ (tones), 8T, 5T, and $12 \mathrm{~m}$ (meters), 10m, 9.6m, 7.2m after storm causes for decades.

Beijing Jingyuanda Logistics registered capital of 500,000 yuan; their business covers in most large and medium-sized cities from different areas including northeast, southeast, northwest, and southwest and other regions. Business scope expanded to more than thirty provincial cities and the company has been a third-party logistics enterprise by forming a set of road transport, air freight, warehousing, cargo handling and storage, packaging and processing.

Beijing Jingyuanda Logistics has a group of young, vibrant and dynamic master of information management staffs, which provides intellectual support to create an "energy, informatization and branding" logistics services in recent ten years. The company is active in the China's logistics industry with its scientific management, standardization of professional service and reasonable transportation price, as well as good corporate reputation. The businesses they deal with are concentrative relatively, including road transport and air transport of goods. Branch offices and representative offices were set up in Shanghai, Guangzhou, Chengdu and other national capital cities, and the Bohai Rim, Yangtze River Delta and Pearl River Delta region by means of the power of information service platform and the advantage of network. And secondary urban goods transport market was erected quickly to realize the real three-dimensional cargo express crisscross between the national cities and provide customers 
with direct door-to-station and door-to-door delivery business.

Progress of its informatization includes:

(1) Took the lead in the industry passed the ISO9001: 2000 quality management system

(2) Establish archives for clients respectively and open free phone helpline 4008 to accept customer calls, business consulting, visiting tracking return visit and customer feed backs or suggestions.

(3) Introduce the computer management and automated inventory management system (see Figure 5). Now there are more than 2,000 customers and more than 500 customers signed with long-term cooperation agreement.

(4) Beijing Jingyuanda Logistics is subordinate to other logistics information platform website for example: China Product Network (http://www.pe168.com), et, instead of having their own website, however, customers and visitors can visit Beijing Jinhyuanda logistics waybill tracking and tracing system (http://www.jingyuanda56.com) and enter order number and verification code for order inquiries, and also can challenge the results of the consultation and make comments or suggestions.

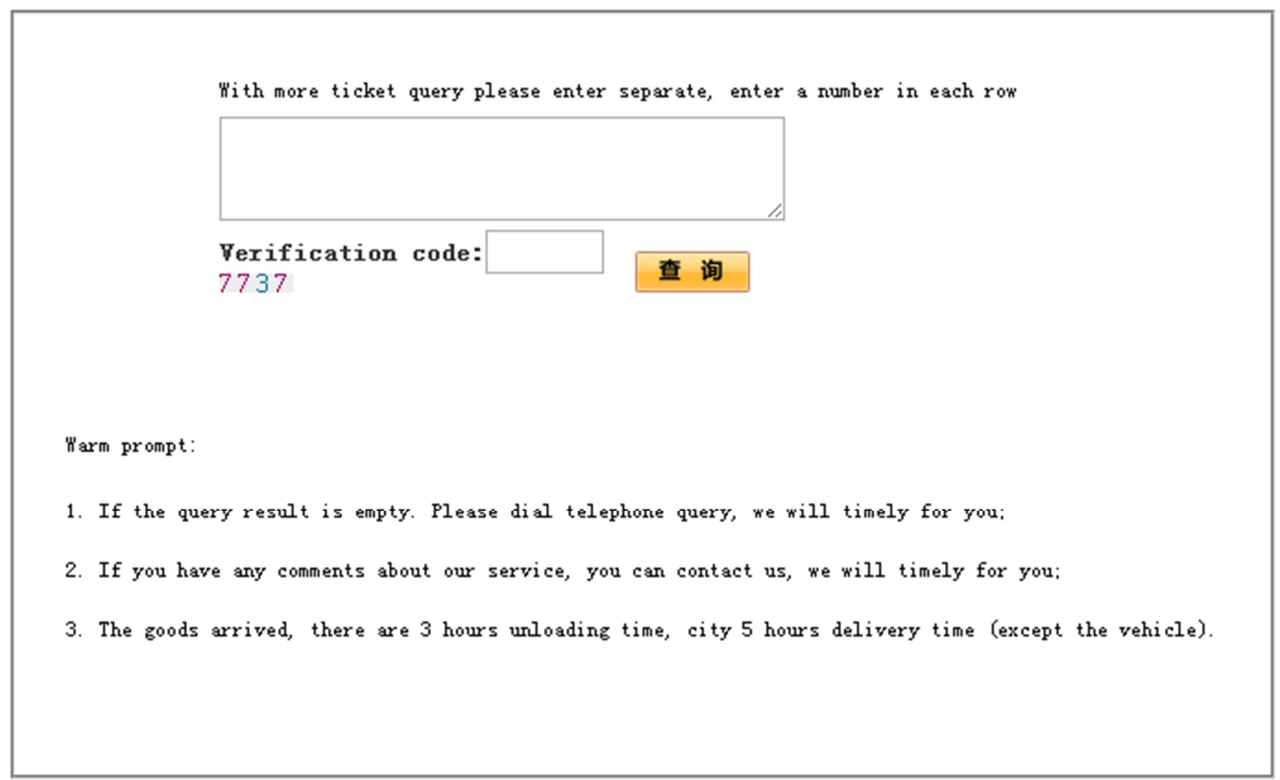

Fig. 5. Automated inventory management system of Beijing Jingyuanda Logistic.

\section{Summary and Prospect}

This paper demonstrates an overview of Beijing-Tianjin-Hebei logistics enterprise information construction and makes an analysis of its deficiencies, which gives the revelation about the informatization construction of logistics enterprises in Beijing-Tianjin-Hebei have made great progress in informatizaiton and the logistics information platform become the new revenue growth point. However, logistics enterprise informatization level needs to be improved compared with the international advanced level [10]. For large and medium-sized logistics enterprises with higher levels of informatization in Beijing-Tianjin-Hebei region, they should strengthen the information sharing and improve overall planning ability of information systems; for small and medium-sized logistics enterprises of the Beijing-Tianjin-Hebei region, they should introduce the advanced information technology and talents to complete the function of information system. It is an opportunity for Beijing-Tianjin-Hebei logistics enterprises to take advantages of the integration of the Beijing-Tianjin-Hebei region to achieve the better development.

\section{Acknowledgments}

The study is supported by Beijing Key Laboratory of Intelligent Logistics System, (BZ0211), and the project of scientific training program for Beijing Wuzi University college students (2016103050), and Beijing Intelligent Logistics System Collaborative Innovation Center.

\section{References}

[1] China Federation of Logistics and Purchasing. (2015). National key enterprise logistics statistical investigation report 2014. Beijing: China Metal Bulletin.

[2] Li Yuanai. (2015). Informatization demands and development countermeasures of small and medium-sized logistics enterprise. Logistics engineering and management, 37 (1), 70-72.

[3] Xu Jing. (2015). Research of the informatized management of the logistics enterprises implement [J]. Journal of Heilongjiang province ecological engineering vocational college, 4, 30-31.

[4] Logistics industry big data platform. http://www.wldl.org/. 
[5] Jiang Yanning. (2011). Hao Shuchi, Lin Meizhen. Study on the current situation of the development of logistics industry in association and the function promotion countermeasures. Journal of logistics technology, 34 (1), 45-47.

[6] Shi Ke. (2011). Study on the current development situation of the logistics information platform in Beijing. Journal of logistics technology, (6), 214-230.

[7] Jiao Wenqi. (2008). Research on regional economic integration of the Beijing-Tianjin-Hebei logistics collaboration. Hebei normal university.
[8] He Jingshi, Yan Hanjun, Zhang Zhiyong. (2013). Transformation and upgrading of logistics industrial growth pattern based on the technological integration. Ecological Economy.

[9] Jia Haojie, Qi Hongmei. (2015). Regional logistics integration of Beijing-Tianjin-Hebei. Manager' Journal.

[10] Wang Wei. (2013). Countermeasures for China's logistics industry to adapt to the development of modern information technology. Financial and Economics. 